\title{
Comparative Study on the Effect of Hot Mud Application and Mustard Application in Patients with Osteoarthritis of Knee. Randomized Controlled Trial.
}

\author{
DR.Dushyant Kumar ${ }^{1}$, DR.Sujatha K J ${ }^{2}$, DR.Prashanth Shetty ${ }^{3}$ \\ ${ }^{\text {I}}$ (Post Graduate Scholar, Department of Post Graduate studies, SDM College of Naturopathy and Yogic \\ Sciences/ Rajiv Gandhi University of Health Sciences, Bangalore, India) \\ ${ }^{2}$ (Dean, Division of Natural Therapeutics, Department of Post Graduate studies, SDM College of Naturopathy \\ and Yogic Sciences/ Rajiv Gandhi University of Health Sciences, Bangalore, India) \\ ${ }_{3}^{3}$ (Principal, SDM College of Naturopathy and Yogic Sciences/ Rajiv Gandhi University of Health Sciences, \\ Bangalore, India)
}

\begin{abstract}
:
Background: Osteoarthritis $(O A)$ is most prevalent chronic rheumatic disease, a leading cause of pain and disability in most countries. The comprehensive use of naturopathy including hot mud and mustard are common. Mustard application lacks scientific evidence while mud is established for treatment of OA. Hence present study aims to evaluate and compare the effect of hot mud and mustard applications to knee in patients with OA.

Material and methodology: Sixty subjects were randomly assigned to either group 1 (hot mud application) or group 2 (mustard application). Subjects received interventions along with naturopathy treatments for ten days with assessments at baseline and post intervention. Assessment tools were Visual Analogue Scale (VAS), Western Ontario and McMaster Universities Secondary Osteoarthritis index (WOMAC), Measurement of range of motion knee by goniometry, and Short form-36 (SF-36).

Results: The results showed significant difference in VAS in both groups. Group 2 showed significant reduction in Womac. Good improvement was seen in group 2 in right extension, left extension, physical functioning, social well-being, general physical health, compared to group 1. Rest of the variables in both groups had similar effects since there was not much significant change in both. The group 1 showed significant difference in pain (31.00+_67.42), when compared to group $2\left(32.67+\_72.42\right)$.

Conclusion: The study result suggests that both hot mud application and mustard application could be considered effective in patients with OA while mustard application is more effective than hot mud application

Keywords: Hot mud application, Mustard application, OA knee, Range of motion, Womac.
\end{abstract}

\section{Introduction}

Osteoarthritis (OA) is a chronic, progressive and disabling joint disease characterized by degenerative change in bones, cartilage, menisci, ligament, and synovial tissue. It can occur in every synovial joint, but is most common in hip and knee joint. ${ }^{[1,2]}$ This is the most common cause of locomotor disability in the elderly. ${ }^{[3]}$

Osteoarthritis is more common in women than men but the prevalence increases dramatically with age. $45 \%$ of women over the age of 65 have symptoms while radiological evidence is found in $70 \%$ of those over 65. ${ }^{[4]}$ Osteoarthritis (OA) has a major impact on functioning and independence and ranks among the top ten causes of disability worldwide. ${ }^{[5,6]}$ Symptoms and disability increase in prevalence with increasing age ${ }^{[7,9]}$ and people with OA use health-care services at a higher rate than a representative group of all adults. ${ }^{[10,11]}$ the number of people with OA disability is expected to double by the year 2020. ${ }^{[12,13]}$ there by increasing the already significant economic burden of OA. Cost of illness studies for OA have focused on the direct costs to the healthcare system. ${ }^{[14,15]}$

Osteoarthritis of knee (OAK) is major cause of mobility impairment, particularly among females. Recent estimates suggest that by 2030, 25\% of US adults will suffer from arthritis. It has been estimated that the percentage of people aged 65 years and above in Asia. It will be more than double in the next two decades, from $6.8 \%$ in 2008 to $16.2 \%$ in 2040 . Middle age and older peoples are most frequently affected and which is more common in women than in men. A survey by world health organization (WHO), in 2000 revealed that incident and prevalence of OA increases with age. In worldwide $9.6 \%$ of men and $18 \%$ of women who aged $>60$ years have symptomatic OA. Recent estimates suggest that by $2030,25 \%$ of US adults will suffer from arthritis. It has been estimated that the percentage of people aged 65 years and above in Asia. ${ }^{[16]}$

Osteoarthritis (OA) is most prevalent of the chronic rheumatic disease and is a leading cause of the pain and disability in most countries worldwide. ${ }^{[17]}$ Osteoarthritis $(0 \mathrm{~A})$ is second most common Rheumatological problem and is most frequent joint disease with prevalence of $22 \%$ to $39 \%$ in India. ${ }^{[18,20]}$ 
Many countries in Asia ageing rapidly .it has been estimated that the percentage of people aged 65 years and over in Asia will more than double in the next two decades, from 6.8\%in 2008 to $16.2 \% 2040$. $^{[21]}$

Pain, stiffness, joint swelling, coarse crepitus, limitations in walking; stair climbing and squatting are common in patient with osteoarthritis of knee (OAK) which greatly interferes with activities of daily living. Most research on knee OA has attempted to quantify the magnitude of physical disability associated with this disease and the impact of various treatments on outcomes such as pain severity and physical functioning. However, the physical manifestations of knee OA have direct impact on other aspects of patient's lives such as social interactions, mental functioning, and sleep quality [and recreation and have a significant negative impact on health related quality of life (HRQOL) which progressively declines with the magnitude of disease progression. $^{[22,23]}$

HRQOL measures are relevant and important adjunct outcomes that help in quantifying the physical, social, and emotional impact of OAK. ${ }^{[24,25]}$ Identification of therapies that improve HRQOL in patients with OAK may mitigate the clinical, economic, and social burden of the disease. ${ }^{26}$

Naturopathy is a system of man building in harmony with constructive principles of nature on physical, mental, moral and spiritual planes of living and consists of non-invasive treatment modalities like diet therapy, fasting therapy, mud therapy, hydro therapy, massage therapy, acupressure, acupuncture, chromo therapy, and magnet therapy. ${ }^{[27]}$

Mud therapy is an important treatment modality used in naturopathy. ${ }^{[28]}$ Mud pack therapy has been used to treat rheumatic conditions since time immemorial, representing an unquestionable reality. ${ }^{[29]}$ However, there are only a few review articles that evaluate the therapeutic effect of its application in knee OA. ${ }^{[30]}$ Which is widely used in our country as in many other countries for the treatment of musculoskeletal diseases due to provision of pain relief. ${ }^{[31]}$ Mustard application to knee is also one of the naturopathic treatment modality used mainly in the clinical practice for the management of OAK in most of the naturopathy clinics/hospitals. Though it is being widely used by the naturopathic physicians, there is lack of scientific evidences for the use of mustard application for OAK and though mud therapy has traditional references, more studies are required to establish the efficacy and usefulness of mud therapy in various diseases. ${ }^{[32]}$ Like OAK made us to select this present study to evaluate and compare the effect of mud application therapy and mustard application to knee in patient with OAK.

\section{Material And Methods}

Subjects:Sixty subjects with ages ranging between 30-65 years participated in study. They were screened through a routine medical checkup and those satisfying diagnostic criteria for osteoarthritis of knees pain were recruited.

Description of subjects including the selection of sample from the population: Study population was selected from inpatient facility of SDM Yoga and nature cure hospital, Shanthivana, Dharmasthla; sixty subjects were recruited for the study based on inclusion and exclusion criteria.

Ethical Considerations: Subjects who fulfilled the inclusion criteria were shown information sheet having details regarding the nature of study and intervention to be used. Subjects were given enough time to go through the study details mentioned in the information sheet. They were given the opportunity to ask any question and if they agree to participate in the study they were asked to sign the informed consent form. All expressed their willingness to participate in the study by giving signed informed consent. Approval was obtained from Institutional Ethical Committee, as all tests were essentially non-invasive in nature.

\section{Inclusion \& exclusion criteria:}

Inclusion Criteria

The following inclusion criteria would be the basis for selecting subjects.

- Subject diagnosed as OAK, according to American College of Rheumatology diagnostic criteria for osteoarthritis of knee will be included in this study.

- Both genders.

- Age: 30 to 65 years.

\section{Exclusion Criteria:}

- Rheumatoid arthritis, fibromyalgia, recurrent or active pseudo-gout, cancer or other serious medical condition

- History of kidney or liver failure

- Oral steroids within the last four weeks

- Intra-articular knee depo-corticosteroids within the previous 3 months

- Intra-articular hyaluronate within the previous 6 months

- Arthroscopy of the knee within the previous year 
- $\quad$ Significant injury to the knee within the previous 6 months

- $\quad$ Rash or open wound over the knee

- $\quad$ Structured exercise more than once per week for 20 minutes or longer during the 3 months prior to study entry

- Anorexiant or other medications known to affect metabolism

- Current or planned pregnancy

Design.

Randomized control trial: Randomization was done by using the chit system. There were equal numbers of subjects (30 each) in Group 1 (hot mud application) and Group 2 (mustard application). They were assessed at the baseline and after 10 days.

\section{Assessments:}

Primary outcome variables:

Visual Analogue Scale (VAS):

The Visual analogue scale was developed by Cline. ${ }^{[33]}$ The visual analogue scale (VAS) provides a continuous scale for subjective magnitude estimation and consists of a straight line, the limits of which carry a verbal description of each extreme of the symptom to be evaluated. The line is usually $10 \mathrm{~cm}$ long and horizontal ${ }^{[34]}$ though different lengths and orientations have been employed and proven satisfactory. ${ }^{[35,36]}$ The subjects will be asked to rate the severity of pain related to low back pain by visual assessment technique with a scale of $0-10 \mathrm{~cm}$.

\section{Patient Global Assessment:}

Western Ontario and McMaster Universities Secondary Osteoarthritis index (WOMAC): is widely used in the evaluation of Hip and Knee Osteoarthritis. It is a self-administered questionnaire consisting of 24 items divided into 3 subscales assess the three dimensions of pain, disability and joint stiffness in knee and hip osteoarthritis. ${ }^{[37]}$

Measurement of range of motion knee by goniometry:

Goniometry: Knee region range of movement (flexion and extension) will be assessed by using goniometry. The normal Knee range of movement, flexion is $0-130$ and extension is $120-0 .^{[38]}$

\section{Secondary Outcome Variables.}

Short Form 36 (SF 36):

The SF-36 is a multi-purpose, short-form health survey with only 36 questions. It yields an 8-scale profile of functional health and well-being scores as well as psychometrically-based physical and mental health summary measures and a preference-based health utility index. ${ }^{[39]}$

\section{Intervention:}

The participants selected for the study were randomly assigned in to Group 1 and Group2.

\section{Group 1 intervention:}

Hot mud application: Mud will be heated up to $45{ }^{\circ} \mathrm{C}$ with the use of hot water then it will be applied to the affected knee covering an area of $5 \mathrm{~cm}$ above and below the patella for 30 minutes daily for the period of 10 days. ${ }^{[40]}$ And standard naturopathy treatment protocol was made which was prescribe in the morning session.

\section{Group 2 interventions:}

Hot mustard application: Mustard powers added to the hot water at the $45^{\circ} \mathrm{C}$ and apply the mustard powder application over the knee. Mustard application to knees for 30 minutes a day for the period of 10 days. Mustard application is useful for the cases in which very quick and strong revulsive effect is desired, as for the relief of severe pain by its chemical irritation. ${ }^{[41]}$ and standard naturopathy treatment protocol was made which was prescribe in the morning session.

\section{Treatment Chart}

Table 1.Naturepathy intervention protocol for 10 days. (Group-1)

\begin{tabular}{|l|l|l|}
\hline DAY & MORNING & AFTERNOON \\
\hline 1 & En;Steam bath & Hot mud application to knee \\
\hline 2 & Souna bath & Hot mud application to knee \\
\hline 3 & Neutral $1 / 2$ bath with salt & Hot mud application to knee \\
\hline 4 & Full body massage & Hot mud application to knee \\
\hline 5 & G.T.Bath & Hot mud application to knee \\
\hline 6 & NUWM & Hot mud application to knee \\
\hline 7 & SGOM & Hot mud application to knee \\
\hline 8 & WPB & Hot mud application to knee \\
\hline
\end{tabular}




\begin{tabular}{|l|l|l|}
\hline 9 & CCJ & Hot mud application to knee \\
\hline 10 & Full Mud Bath & Hot mud application to knee \\
\hline
\end{tabular}

Treatment Chart

Table 2.Naturepathy intervention protocol for 10 days. (Group-2)

\begin{tabular}{|l|l|l|}
\hline DAY & MORNING & AFTERNOON \\
\hline 1 & En;Steam bath & Hot mustard application to knee \\
\hline 2 & Souna bath & Hot mustard application to knee \\
\hline 3 & Neutral $1 / 2$ bath with salt & Hot mustard application to knee \\
\hline 4 & Full body massage & Hot mustard application to knee \\
\hline 5 & G.T.Bath & Hot mustard application to knee \\
\hline 6 & NUWM & Hot mustard application to knee \\
\hline 7 & SGOM & Hot mustard application to knee \\
\hline 8 & WPB & Hot mustard application to knee \\
\hline 9 & CCJ & Hot mustard application to knee \\
\hline 10 & Full Mud Bath & Hot mustard application to knee \\
\hline
\end{tabular}

\section{Data extraction and Analysis:}

Data extraction: The data was collected using three primary outcomes variables and one secondary outcome variables. The assessments were collected on the first day (baseline data) and the end of 10 days (post data). The data was organized in Microsoft Excel Sheets (version 2010).

Data Analysis: Data were analysed using IBM SPSS 21.0. The data was checked for normality and Mann Whitney U test was employed to compare means between the two groups. For all the analysis, we present $95 \%$ confidence intervals and considered $\mathrm{p}<0.05$ as significant

\section{Results}

The present study was conducted to compare and evaluate if hot mud application and mustard application had any influence on Visual analogue scale (VAS) for pain. Patient Global Assessment Western Ontario and McMaster Universities Secondary Osteoarthritis index (WOMAC), goniometry (range of motion), Short Form 36 (SF 36) and quality of life in patients with osteoarthritis of knee for short term duration result were compared with two groups, group 1(hot mud application) and group 2(mustard application), wherein data was extracted at both baseline and post intervention. Both (group1 and group2) have same effect on reducing pain (VAS) (fig.1). The results showed significant difference in grouplin severity of pain. Group 2 showed significant reduction in Womac (fig.2) and there was much improvement seen in the mustard application (group2) in right extension, left extension, physical functioning ,social well-being, general physical health, compare to mud application group. And rest of the variable in both hot mud and mustard has similar effect since there is not much significant change in both the group in (SF-36). Mann-Whitney U test was done for comparison between two groups. Group 2 has shown significant difference in range of motion (goniometry). Group 1 showed significant difference in pain (31.00+_67.42), when compare to group 2. (32.67+_72.42). (fig.3)

\section{Discussion}

The main aim of the study was to evaluate and compare the effect of hot mud application and mustard application is in general to reduce pain intensity(VAS) and patients global assessment, range of motion, improve the quality of life and health status in patient with osteoarthritis of knee.

We investigated the use of hot mud application and mustard application treatment before and after in patients with osteoarthritis of knee. We used self-reported visual analogue scale, patients global assessment (WOMAC-Western Ontario and McMaster Universities Secondary Osteoarthritis index),range of motion(goniometry)and SF-36(to measure health related quality of life).these methods have been reported to be most satisfactory for assessing severity of pain, patients global assessment, range of motion and HRQoL.

In our present study, we found that pain score reduce in hot mud application compare to mustard application. Which suggest the main use of the treatment is to relieve rheumatic musculoskeletal pain. ${ }^{[42]}$ Its effects on neuralgias and skin problems are also known for the successful results obtained. ${ }^{[43]}$ Although the main mechanical action of the mud pack is thermal therapeutic, its systemic action allows it to act on molecular and chemical processes in degenerative conditions like, ${ }^{[44]}$ mud application has a therapeutic activity due to both anti-inflammatory component and thermal effect ${ }^{[45]}$ with mad application we observed an improvement in pain and quality of life parameters. Mostly superficial heating therapy including paraffin baths, hot packs, mud application, balenotherapy and mineral water. The common action mechanism is to increase pain threshold by affecting sensory and muscle nerve and muscle nerve endings. Beta endorphin releasing and washing out the pain mediators by peripheral releasing and washing out the pain mediators by peripheral vasodilation also play a role in producing analgesia and sedation..${ }^{46]}$ 
Mustard application to knee is also one of the naturopathic treatment modality used mainly in the clinical practice for the management of OAK in most of the naturopathy clinics/hospitals. Though it is being widely used by the naturopathic physicians, there is lack of scientific evidences for the use of mustard application for OAK and though mud therapy.

The study was able to prove the hypothesis that use of hot mud application and mustard application for a short term duration of 10 days as an adjuvant to naturopathy modality is effective in the treatment of osteoarthritis of knee. Although both the treatment modalities are effective but mustard is more effective. Mustard application showed significant reduction in Womac scale and there was much improvement seen in the mustard application (group2) in right extension, left extension, physical functioning, social well-being, general physical health, quality of life compare to mud application group.

\section{Conclusion}

The study results showed improvement in severity of pain, patient's global assessment (WOMAC) in both the both group and there was not much change seen in the range of motion (goniometry) in both the group. Both hot mud application and mustard application showed improvement in VAS, WOMAC, ROM and SF-36 within the group which suggests that hot mud application and mustard application along with naturopathy intervention can be considered as effective treatments in patients with osteoarthritis of knee pain.

\section{Acknowledgements}

We thank the volunteers who participated in the study .we thank principal Dr.Prashanth shetty, Dr.Getta B Shetty and statistician Dr.Vadiraja for their required support to complete this project successfully.

\section{References}

[1] Hunter DJ, Arden N, Conaghan PG, Eckstein F, Gold G, Grainger A, et al, Definition of osteoarthritis on MRI: results of a Delphi exercise. Osteoarthritis Cartilage, 19, 2011, 963-969.

[2] Marijnissen AC, Vincken KL, Vos PA, Saris DB, Viergever MA, Bijlsma JW, et al, Knee Images Digital Analysis (KIDA): a novel method to quantify individual radiographic features of knee osteoarthritis in detail, Osteoarthritis Cartilage, 16, 2008, $234-243$.

[3] A Mahajan, S Verma, V Tandon, et al, Osteoarthritis, Post Graduate Department of Medicine, Post Graduate Department of Pharmacology and Therapeutics, Government Medical College, Jammu Received, 6.2.2005; Revised, 4.3.2005, Re-revised, 1.6.2005, Accepted, 3.6.2005, JULY, 53, 2005.

[4] Brooks PM, et al, Rheumatology, Medical Journal of Australia, 1998, 8-45.

[5] Murray CJL, Lopez AD, Eds, et al, The global burden of disease: a comprehensive assessment of the mortality and disability from diseases, injuries and risk factors in 1990 and projected to Boston: Harvard School of Public Health on behalf of the World Health Organization, and the World Bank, 1996.

[6] Badley EM, Rasooly I, Webster G, et al, The impact of musculoskeletal disorders in the population: are they aches and pains? Findings from the 1990 Ontario Health Survey Rheumatol, 22,1995,733-739.

[7] Hawker GA, Wright JG, Coyte PC, et al, Determining the need for hip and knee arthroplasty, the role of clinical severity and patients' preferences, Med Care, 39, 2001, 206-216.

[8] Badley EM, Williams JI, Eds, et al, Patterns of health care in Ontario, Arthritis and related conditions, An ICES Practice Atlas, Toronto, Institute for Clinical Evaluative Sciences, 1998.

[9] Reynolds DL, Chambers LW, Badley EM, et al, Physical disability among Canadians reporting musculoskeletal diseases, J Rheumatol, 19,1992,1020-1030.

[10] Bridges-Webb C, Britt H, Miles DA, Neary S, Charles J, Traynor V, et al, Morbidity and treatment in general practice in Australia, AustFam Physician, 22, 1993, 336-339,342-346.

[11] Felts W, Yelin E, et al, The economic impact of rheumatic diseases in the United States, J Rheumatol, 16, $1989,867-884$.

[12] Gabriel SE, Crowson CS, Campion ME, O'Fallon WM, et al, Direct medical costs unique to people with arthritis, J Rheuzmatol, 24,1997,719-725.

[13] Badley EM, et al, Population projections and the effect on rheumatology, Ann Rheum Dis, 50, 1991, 3-6.

[14] Elders MJ, et al, The increasing impact of arthritis on public health, J Rheumatol, 27(60), 2000, 6-8.

[15] Lanes SF, Lanza LL, Radensky PW, et al, Resource utilization and cost of care for rheumatoid arthritis and osteoarthritis in a managed care setting, Arthritis Rheum, 40,1997,1475-1481.

[16] Kinsella K, He W, et al, An Ageing World, 2008, U.S. Census Bureau, Washington, DC, 2009.

[17] World Health Organization (2002) World Health Report 2002, Reducing Risks, Promoting Healthy Life, Geneva, WHO.

[18] Chopra A, Patil J, Bilampelly V, et al, The Bhigwan (India) COPCORD, Methodology and first information report, APLAR, J Rheumatol, 1,1997,145-154.

[19] Chopra A, Patil J, Bilampelly V, Relwane J, Tandle HS, et al, Prevalence of rheumatic disease in rural population in Western India, A WHO-ILAR-COPCORD study, J Assoc Physicians India, 49,2001,240-246.

[20] Mahajan A, Jasrotia DS, Manhas AS, Jamwal SS, et al, Prevalence of major rheumatic disorders in Jammu. JK Science, 5, 2003, 63-66.

[21] Kinsella K, He W, et al, An Ageing World, 2008, U.S. Census Bureau, Washington, DC, 2009.

[22] Snider MG, MacDonald SJ, Pototschnik R, et al, Waiting times and patient perspectives for total hip and knee arthroplasty in rural and urban Ontario, Can J Surg, 48,2005,355-360.

[23] Hoogeboom TJ, den Broeder AA, de Bie RA, van den Ende CH, et al, Longitudinal impact of joint pain comorbidity on quality of life and activity levels in knee osteoarthritis, data from the Osteoarthritis Initiative, Rheumatology (Oxford), 52,2013,543-546.

[24] Ferrell BA, et al, Pain management in elderly people, J Am Geriatr Soc, 39, 1991, 64-73.

[25] Revicki DA, et al, Health-related quality of life in the evaluation of medical therapy for chronic illness, J FamPract,29,1989,377380 .

[26] White PH, Waterman M, et al, Making osteoarthritis a public health priority, Am J Nurs, 112, 2011, 20-5. 
[27] Dept. of AYUSH, Ministry of health and family welfare, Govt. of India.

Retrievedfrom:http://indianmedicine.nic.in/index3.asp?sslid=187\&subsublinkid=36\&lang=1.

[28] Rajiv Rastogi, et al, Therapeutic uses of Mud therapy in Naturopathy, Indian journal of traditional knowledge, 1(3), 2012, 556-559.

[29] Flurin R, et al, Histoire du thermalisme, Press ThermClimat, 43, 2006, 45-97.

[30] Maraver F, et al, Antecedenteshistó ricos de la peloterapia, An Hidrol Med, 1, 2006, 17-42.

[31] Chadzopulu A, Adraniotis J, Theodosopoulou E, et al, The therapeutic effects of mud, Prog Health Sci,1,2011,132-136.

[32] Karagülle MZ, et al, Kaplıcatedavisininetkinliği, KlinikGelişim, 13, 2000, 258-261.

[33] Cline (M.E), et al, Standardization of visual analogue scale, Nurs Res, 41, 1992,378.

[34] Huskisson EC, et al, Measurement of pain, Lancet, II, 1992, 1127, 113-116.

[35] Revill SI, Robinson JO, Rosel M, Hogg MIJ, et al, the reliability of a linear analogue for evaluating pain Anaesthesia,31,1976,11911198.

[36] Scott J, Huskisson EC, et al, Vertical horizontal visual analogue scales, All Rheum Dis,38,1979,560.

[37] Baron G, Tubach F, Ravaud P, Logeart I, Dougados M, et al, Validation of a short form of the Western Ontario and McMaster Universities Osteoarthritis Index function subscale in hip and knee osteoarthritis, Arthritis Care Res, 57,2007,633-638.

[38] Gajdoslk RL, Bohannon RW, et al, Clinical measurement of range of motion, Physther, 67, 1987, 1867-1872.

[39] John E. Ware, Jr., PhD, et al, SF-36 Health Survey Update, Available from, http://www.sf-36.org/tools/SF36.shtml.

[40] Nature cure treatment by institute of naturopathy and yogic, seventh revised enlarged edition, 1994; 55-57.

[41] J.H.Kellogg, et al, Rational hydrotherapy a manual of the physiological and therapeutic effect of hydriatic procedures, and the technique of their application in the treatment of disease, National institute of naturopathy, II, 2005,1338,814.

[42] Armijo M, et al, Peloterapia en lasenfermedadesreuma' ticas, ReumatolPract, IV, 1981, 103-110.

[43] Bellometti S, Giannini S, Sartori L, Crepaldi G, et al, Cytokine levels in osteoarthritis patients undergoing mud bath therapy, Int J Clin Pharm Res, XVII, 1997,149-153.

[44] Meijide R, Mourelle L, et al, Peloides en lasenfermedades del aparatolocomotor, In Legido Soto JL and MourelleMosqueira ML, eds, Investigaciones en el a' mbito iberoamericanosobre peloidestermales, Vigo, Publicaciones Universidad de Vigo, 21, 2007, 277290.

[45] Bellometti S, Cecchettin M, Galzigna L, et al, Mud pack therapy in osteoarthrosis, changes in serum levels of chondrocyte markers, ClinChimActa, 1997,268,101e6.

[46] Curkovic B, Vitulic V, Babic-Naglic D, Durrigl T, et al, The influence of heat and cold on the pain threshold in rheumatoid arthritis, Z Rheumatol, 2,1993;52.

Trial Profile: An illustration of participation of subjects in the trial from its inception till the completion.

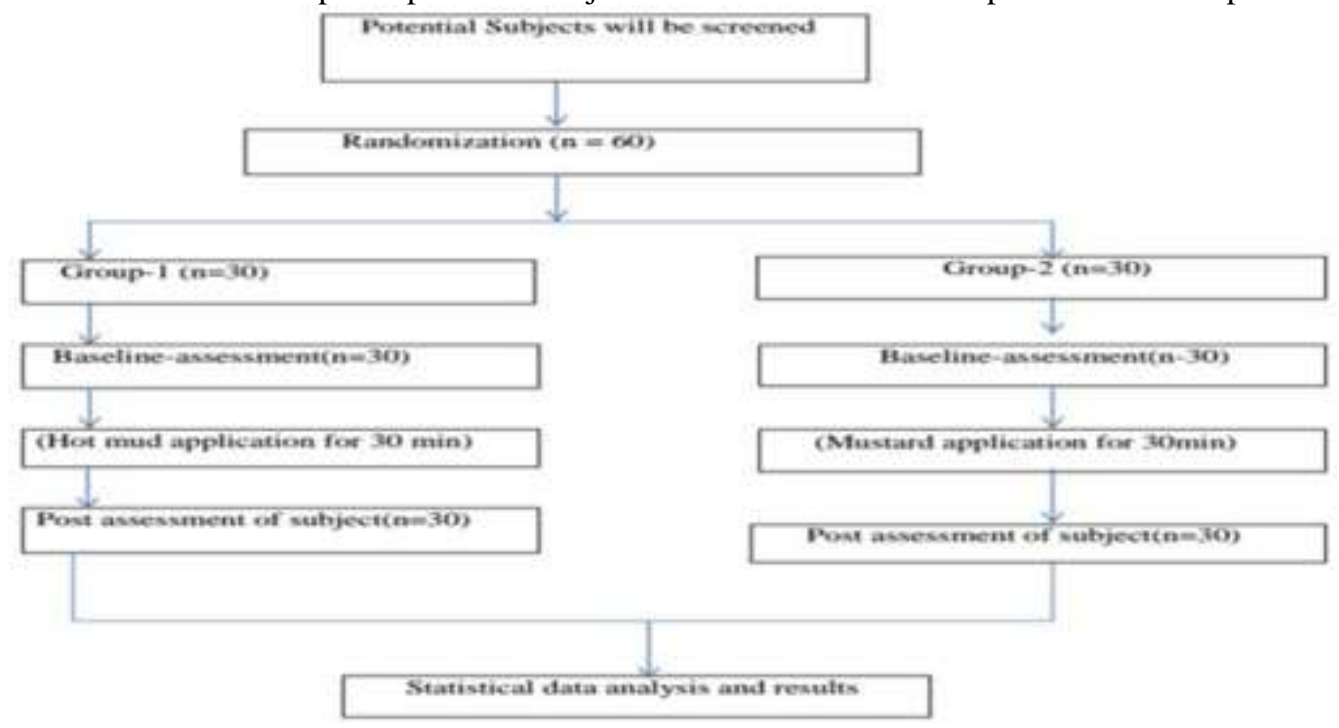

Fig.1: Comparison between (VAS) [pre and post of hot mud application (Group-1)] and [pre and post of mustard application (Group-2)].

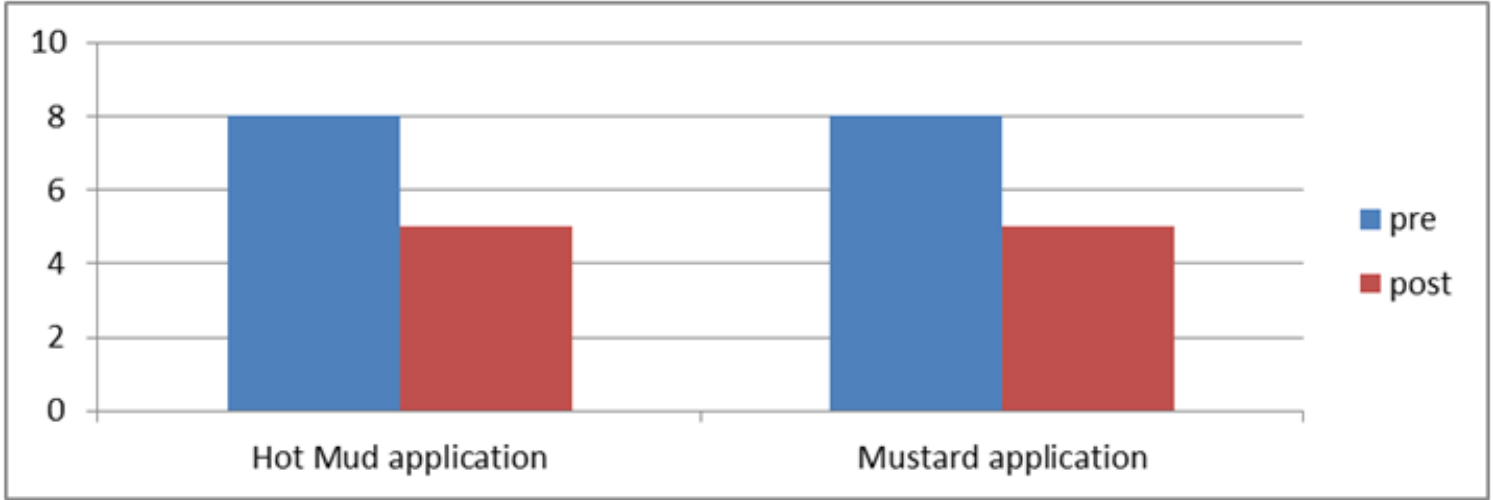


Fig.2: Comparison between post groups (WOMAC \%)( hot mud application (1), mustard application (2)).

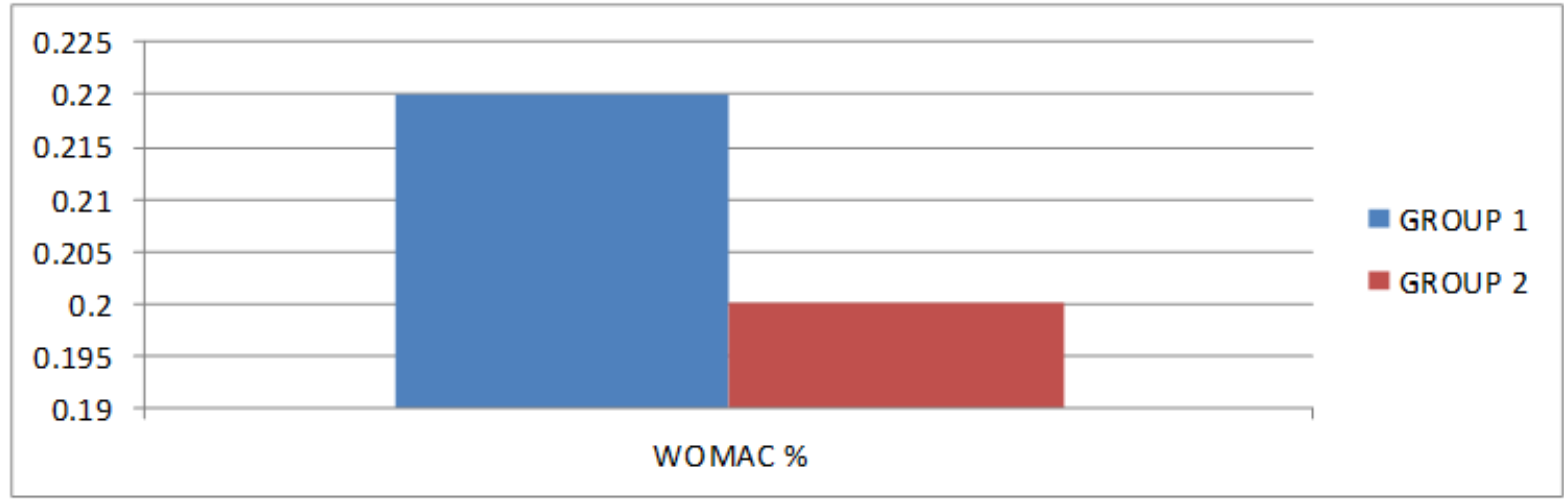

Fig.3 Comparison between post group (pain, general health) (hot mud application (1), mustard application (2)).

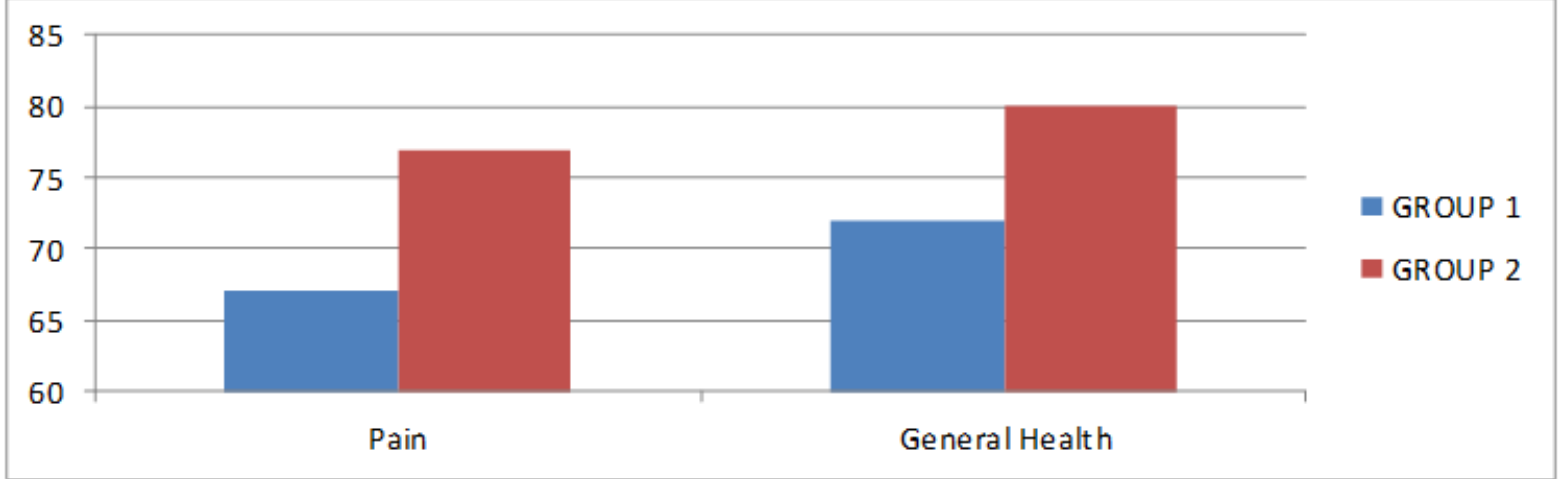

Table 1: Represent post intervention of group 1(hot mud application) and group 2(mustard application).

\begin{tabular}{|c|c|c|c|c|}
\hline VARIABLES ( post intervention) & $\begin{array}{lr}\text { GROUP } & 1 \\
\text { (HOT } \quad \text { Mud } \\
\text { APPLICATION) } \\
\text { Sample median } \\
\end{array}$ & $\begin{array}{l}\text { GROUP } \\
\text { (MUSTARD } \\
\text { APPLICATION) } \\
\text { Sample median } \\
\end{array}$ & $\begin{array}{ll}\text { Mann-Whitney } & \text { U } \\
\text { test statistic } & \text { P- } \\
\text { VALUE } & \end{array}$ & CONCLUSION \\
\hline VAS & $5.00(0.58)$ & $5.00(0.56)$ & 401.00 & 0.35 \\
\hline WOMAC \% & $0.22(0.02)$ & $0.20(0.03)$ & 676.00 & 0.00 \\
\hline goniometry right extension & $170.0(1.83)$ & $170.0(3.79)$ & 362.50 & 0.01 \\
\hline goniometry right flexion & $80.0(1.64)$ & $80.0(6.40)$ & 475.50 & 0.56 \\
\hline goniometry left flexion & $80.0(1.78)$ & $80.05 .56)$ & 435.00 & 0.72 \\
\hline goniometry left extension & $170.00(1.83)$ & $170.00(3.13)$ & 377.00 & 0.02 \\
\hline physical functioning & $80.0(2.25)$ & $80.0(1.27)$ & 308.00 & 0.00 \\
\hline physical health & $100.00(0.00)$ & $100.00(4.56)$ & 465.00 & 0.32 \\
\hline emotional problem & $100.00(0.00)$ & $100.00(0.00)$ & 450.00 & 1.00 \\
\hline energy fatigue & $65.0(1.60)$ & $65.0(2.01)$ & 393.50 & 0.16 \\
\hline emotional well being & $92.0(2.64)$ & $92.0(4.69)$ & 463.00 & 0.84 \\
\hline social well being & $75.0(3.28)$ & $75.0(9.25)$ & 348.00 & 0.06 \\
\hline pain & $67.0(2.97)$ & $77.0(8.62)$ & 260.50 & 0.00 \\
\hline general health & $72.0(4.01)$ & $80.0(5.15)$ & 118.50 & 0.00 \\
\hline
\end{tabular}

